\title{
Tumbas de Coporaque. Aproximaciones a concepciones funerarias collaguas
}

Tombes de Coporaque. Approches des pratiques funéraires Collaguas

The Tombs of Coporaque. Approximations of Collaguas Funerary Conceptions

\section{Frédéric Duchesne}

\section{(2) OpenEdition}

Edición electrónica

URL: http://journals.openedition.org/bifea/4963

DOI: $10.4000 /$ bifea.4963

ISSN: 2076-5827

\section{Editor}

Institut Français d'Études Andines

\section{Edición impresa}

Fecha de publicación: 1 diciembre 2005

Paginación: 411-429

ISSN: 0303-7495

\section{Referencia electrónica}

Frédéric Duchesne, «Tumbas de Coporaque. Aproximaciones a concepciones funerarias collaguas », Bulletin de l'Institut français d'études andines [En línea], 34 (3) | 2005, Publicado el 08 diciembre 2005, consultado el 01 diciembre 2020. URL : http://journals.openedition.org/bifea/4963 ; DOI : https:// doi.org/10.4000/bifea.4963

\section{(@) $(\mathcal{Q} \Theta \Theta$}

Les contenus du Bulletin de l'Institut français d'études andines sont mis à disposition selon les termes de la licence Creative Commons Attribution - Pas d'Utilisation Commerciale - Pas de Modification 4.0 International. 


\title{
Tumbas de Coporaque. Aproximaciones a concepciones funerarias collaguas
}

\author{
Frédéric Duchesne*
}

\section{Resumen}

A partir de observaciones arqueológicas de una necrópolis del área Collagua y del análisis de fuentes etnohistóricas de archivos, este artículo propone un intento de interpretación de la función de las sepulturas y de las prácticas funerarias de la sociedad collagua.

Palabras clave - collagua, Colca, prácticas funerarias, muerte, antepasados, chullpa

\section{Tombes de Coporaque. Approches des pratiques funéraires Collaguas}

Résumé

Combinant les observations archéologiques d'une nécropole Collagua et l'analyse de documents ethnohistoriques issus d'archives, cet article propose un essai d'interprétation de la fonction des sépultures et des pratiques funéraires de la société Collagua.

Mots clés - Collagua, Colca, pratiques funéraires, mort, ancêtres, chullpa

\section{The Tombs of Coporaque. Approximations of Collaguas Funerary Conceptions}

\begin{abstract}
Using archaeological data from a Collagua necropolis and etnohistorical records from archives, this article offers an interpretation of the function of graves and funerary practices in Collagua society
\end{abstract}

Key words - Collagua, Colca, funerary practices, death, ancestors, chullpa 
Una tarde de julio 1846, en el camino entre Arequipa y Lampa, el explorador francés Paul Marcoy y su guía Ñor Medina, fueron sorprendidos por una fuerte tormenta invernal. En medio de las alturas del norte de Arequipa, en tierra Collagua, encontraron un refugio poco común:

«El refugio que acabamos de descubrir tan oportunamente era una construcción de bloques enormes, cubierta por uno monolítico. Una pequeña ventana, a la altura de un hombre, y orientada hacia el oriente, apenas si alumbraba el interior. El sepulcro, pues se trataba de uno, podía tener unos diez pies cuadrados por ocho de altura. Sus muros en talud, como los de las construcciones egipcias, y de un enorme espesor, probablemente habían visto pasar muchos siglos y soportado muchas tempestades. Le pregunté a mi guía qué pensaba al respecto, y si había alguna tradición sobre la tumba, pero la nieve, al calar su ropa, había secado su habitual locuacidad, y me respondió con un bostezo: “Es obra de los gentiles aimaras"» (Marcoy, 2001 [1869]: 135).

Marcoy afirma, según lo que aprendió durante su viaje, que los «aimaras» eran descendientes de «la nación de los Collaguas» que «habían venido en antiguos tiempos de un país lejano situado al norte del Perú»1. Sin poder confirmar los dichos de Marcoy y atribuir a los collaguas este origen, es manifiesto que aquellos formaban parte de los numerosos pueblos de habla

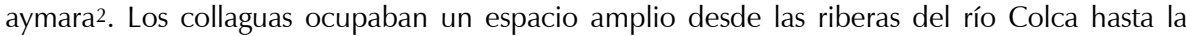
ciudad actual de Arequipa y tenían efectivamente lazos estrechos con los demás pueblos aymara del altiplano desde el Intermedio Tardío (1100-1400 d. C.)3. Así la sepultura que descubrió Marcoy recuerda las del altiplano boliviano. Al pasar su noche en grata y silenciosa compañía, Marcoy aprovechó su descanso para describir su extraño refugio, dejando a la posteridad una de las únicas descripciones de una sepultura collagua intacta:

«La forma de inhumación usada por estos indios en la época de su esplendor es también asaz extraña, y no se observa en ninguna de las demás naciones de América del Sur. Sus tumbas, llamadas chullpas, tenían la figura de una pirámide truncada de veinte a treinta pies de altura. Una pirámide que, construida de adobes, tenía varias hiladas en receso, y recordaba, por su configuración general, los teocallis mejicanos, cuyo modelo parece haber sido tomado en préstamo al templo de Bel. A veces las tumbas de los aimaras eran simples monumentos construidos en aparejo ciclópeo, cubiertos por un techo monolítico, y cuyo interior comprendía una habitación cuadrada —en la que escribo estas líneas - con una puerta baja hacia el poniente y una pequeña ventana orientada hacia el oriente. A veces, no obstante, estas tumbas tenían la forma de obelisco cuya altura, de ocho a diez metros, era el doble de anchura de sus base, y estaban cubiertas por un techo inclinado y construido de barro y paja». (Marcoy, 2001 [1869]: 138-139)

A la manera de los demás viajeros de los Andes del siglo XIX, llamó mucho la atención de Marcoy la importancia de las sepulturas y de los muertos en las antiguas culturas andinas, que

1 «Los aimaras, que asignaban a estas construcciones una fecha muy remota, las atribuían a la nación de los collaguas, cuyos descendientes pretendían ser. Según ellos había venido en antiguos tiempos de un país lejano, situado al norte del Perú, y se había detenido por largo tiempo en diferentes lugares antes de alcanzar la región de las mesetas peruana, la misma que, en recuerdo suyo, había llevado desde entonces el nombre de Collao». (Marcoy, 2001 [1869]: 135) Una fuente del siglo XVI nos indica también el origen norteño de los Collaguas: «tienen para sí de noticia que se dan heredada de padres a hijos, que proceden de una guaca o adoratorio antiguo questá en los términos de la provincia de Vellilli, comarcana desta, ques un cerro nevado a manera de volcán, señalando de los otros cerros que por allí hay, el cual se llama Collaguata». (Ulloa de Mogollón, 1965 [1586]: 327) El lingüista Alfredo Torero (2002) piensa que la introducción de la lengua se hizo en el altiplano desde el norte y la cordillera occidental.

2 «Los Collaguas usan generalmente dos lenguas: el aymara y la tiene por propia y natural, aunque algunos pueblos de los Collaguas, como son los de Pinchollo é Calo é Tapay, usa y habla cada pueblo diferente del otro, muy bárbara, é que si no son ellos entre sí no la entienden, aunque están unos pueblos muy cercanos de otros; y no por esto dejan estos pueblos de hablar la lengua aymara, questa es la general». (Ulloa de Mogollón, 1965 [1586]: 327)

3 Entre otros, Neira Avendaño, 1964; Pease, 1977; Galdos Rodríguez, 1985. 
ya habían notado los cronistas de los siglos XVI y XVII (Véase Cieza de León, 1988 [1553]; Polo de Ondegardo, 1916 [1571]; Mercado de Peñaloza, 1965 [1586]; Álvarez, 1998 [1588]; Guamán Poma de Ayala, 1980 [1615]; Ramos Gavilán, 1976 [1621]). Si las sepulturas del lago Titicaca y del altiplano boliviano descritas por d'Orbigny (2002 [1839]) o Squier (1974 [1877]) han dado una cantidad creciente de estudios y publicaciones en el siglo XX, desde los pioneros que fueron Nordenskiöld 1953 [1906], Tschopik (1946), o Ryden (1947) hasta los estudios contemporáneos ${ }^{4}$, las chullpas collaguas no despertaron el mismo entusiasmo que sus semejantes atliplánicas. A pesar del mayor interés que suscitaron los Collaguas desde los años 60, tanto en la arqueología - desde los primeros estudios arqueológicos serios del Dr. Máximo Neira Avendaño $(1961 ; 1964)$ hasta los de Denevan $(1986 ; 1988)$ — como en la historia — con los estudios notables de Pease (1977), Benavides (1989; 1992), Cook (1982) o Robinson (2003) — no se conocen estudios sobre las concepciones y prácticas funerarias de los collaguas. Máximo Neira Avendaño (1990: 5-184) había ya señalado varios sitios funerarios pero sin más interpretación. En 2003, Steve Arlyn Wernke acabó el primer estudio de síntesis completo sobre la arqueología y la historia de los collaguas y dedicó un capítulo a la arquitectura funeraria de los antiguos habitantes de las riberas del Colca (Wernke, 2003: 225-234). Su enfoque contempló el sitio de San Antonio/Chirpa ubicado cerca del pueblo de Coporaque dando una descripción formal sin entrar más en detalle.

En los meses de enero 2003 y 2004 hice un reconocimiento, con medios escasos, en el valle del Colca. Sin saber entonces de los estudios de Wernke, encontré también las tumbas del sitio de San Antonio/Chirpa, llamado también por la gente del lugar, Yuraqaqa 5 . El estudio descriptivo de Wernke que no localizó varias tumbas de mayor interés se halla entonces completado por el mío. Esos hallazgos permiten plantear varias preguntas de importancia para acercarse a una mayor comprensión de las prácticas funerarias Collaguas.

\section{LA NECRÓPOLIS DE YURAQAQA}

El pueblo de Coporaque (3 575 m.s.n.m.) está ubicado en la ribera derecha del Colca, a 8 kilómetros al oeste de Chivay, actual capital de la provincia de Caylloma. Corporaque está encerrado entre el Colca y el relieve montañoso llamado Masita, dominado por el nevado Mismi (o Huillacayo6), subiendo un espolón rocoso (de orientación aproximada norte-sur) del Masita por su falda este, cerca de Coporaque al oeste.

Toda la falda está cubierta por antiguas terrazas agrícolas abandonadas. En la punta sur del espolón se encuentra un sitio de habitación, que domina el lugar denominado San Antonio, ruinas incas que fueron las más importantes de la región7. En la cumbre del espolón se hallan una serie de construcciones circulares concéntricas. Esta estructura recuerda los pukaras seguramente fortalezas (Hyslop, 1976: 101-102)— descritos por Cieza de León (1988 [1553]: 230-231).

En una primera parte de la falda están concentradas una veintena de pequeñas construcciones semi-subterráneas, especie de cuevas de unos 50-100 cm en el talud de la montaña, cerradas por una bóveda de piedras y tapadas por rocas. Estos edificios evocan las cuevas funerarias ubicadas en las faldas de las montañas descritas en las crónicas y extirpaciones de idolatrías (Duviols, 1986: 2003) . Este sitio será llamado «sitio funerario 1».

4 Son innumerables los estudios consagrados a las torres funerarias. Citemos Hyslop, 1977; Gisbert, 1994; Pärssinen, 1993; 2003 y Kesseli et al., 1999; 2003.

5 Yuraqaqa o «roca blanca», así llaman este sitio los habitantes de los entornos, que todavía siguen honrando. Cuando volví allá en enero 2004 después de un año noté que los cráneos expuestos de las tumbas 14, 15, 16 y 17 habían sido movidos, y que unos tenían ofrendas de hojas de coca frescas.

6 Según mapa IGN sd 19-13.

7 «Oré, fraile Franciscano que vivió en Coporaque a finales del siglo XVI, cuenta que Mayta Capac Inca tuvo por mujer a Mama Yacchi, india natural de este pueblo. Los indios de Coporaque hubieran entonces un grande palacio de cobre para el Inca y su mujen» (Oré, 1992 [1598]: 159). 
El material cerámico encontrado por otros estudiosos en todo el sitio atestigua una ocupación desde el Horizonte Medio (tiestos de cerámica muestran rasgos wari) hasta el Horizonte Tardío (Treacy, 1994: 91-111). Sin embargo, la contemporaneidad de utilización de los diferentes edificios y construcciones del sitio quedan por demostrar.

Al sur del «sitio funerario 1», en el punto en que el talud encuentra la pared vertical del espolón, he localizado un «sitio funerario 2»: 18 tumbas8 edificadas sobre el suelo a la manera de pequeñas casas funerarias, una tras otra durante unos $300 \mathrm{~m}$. Este tipo de construcción es típico del Intermedio Tardío y puede ser atribuido a los collaguas (Wernke, 2003), que ocupaban este lugar en aquel periodo.

La idea de los constructores fue obviamente aprovecharse al máximo del sitio mismo. Así, todas las tumbas se apoyan en la pared de la montaña y a menudo tapan una cueva natural. El sitio está como cuajado de tumbas y da la clara impresión que los constructores quisieron tapar los huecos, las aberturas de la montaña — desde la pequeña falla hasta la grande caverna — para dedicarle a sus muertos.

Si básicamente todas las tumbas tienen el mismo estilo arquitectónico, su forma puede variar según el lugar donde se encuentran. Así la tumba puede ser una simple cueva tapada por un muro (fig. 1) cuyo tamaño puede variar (tumba $4,7,8$ y 9), o un edificio más complejo con tres muros y un techo (fig. 2). Tienen un aspecto de «casita funeraria» que tiene, en promedio, unos $200 \mathrm{~cm}$ de altura, $300 \mathrm{~cm}$ de largo por $100 \mathrm{~cm}$ de ancho. Los muros tienen entre 30 y $50 \mathrm{~cm}$ de grosor. Las tumbas tienen una o varias aberturas de tamaño reducido (aproximadamente $60 \mathrm{x}$ $40 \mathrm{~cm}$ ) delimitas por dinteles de piedras. Todas han sido construidas con piedras pegadas con argamasa gruesa. Parece que el exterior estaba totalmente cubierto con esta misma argamasa, como lo demuestran varias huellas sobre los muros exteriores (tumba 4 y 14). Huellas de pintura o estuco pueden también observarse en el interior de la tumba 14.

Son de plantas cuadrangulares. En las más completas se puede observar dos niveles, una cornisa en el nivel superior y varias cámaras funerarias. En algunas (tumba 5, 7, 9, 11 y 12), el techo se inicia a manera de falsa bóveda (o intento de falsa bóveda) y el monumento está tapado por largas láminas de piedras.

Construidas sobre la falda este del espolón rocoso y apoyadas a su pared, las aberturas de las tumbas están naturalmente dirigidas no

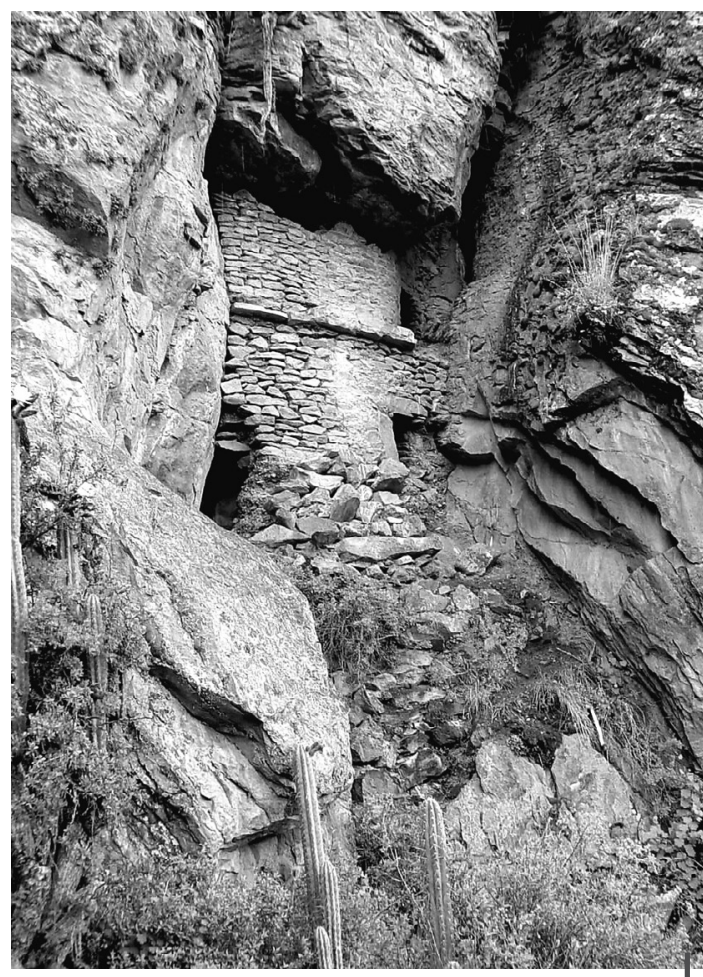

Figura 1 - La tumba 9, simple muro tapando la gran cueva Foto: Frédéric Duchesne solamente hacia el este sino también hacía el nevado Huarancate. Debido a la importancia de la orientación de los edificios funerarios - muy a menudo hacia el este o un cerro sagrado- es muy probable que este sitio fuese escogido en razón de su orientación «ideal».

8 La descripción en detalle de las tumba del sitio se encuentra al final de este artículo. 
Hoy en día, todas las tumbas se hallan saqueadas. El material arqueológico ha sido totalmente disturbado y a menudo echado a fuera de las tumbas. Se encuentra una gran cantidad de huesos humanos en cada tumba (por lo menos 16 individuos en la tumba 7) y numerosos fragmentos de cestas y textiles de baja calidad o de confección más fina (tumba 1, 17 y 18).

\section{RECONSTRUCCIÓN HIPOTÉTICA DE LA ORGANIZACIÓN INTERIOR DE UNA TUMBA}

El número importante de huesos humanos que cubre toda la superficie de cada tumba y del sitio, indica claramente un uso colectivo de las sepulturas.

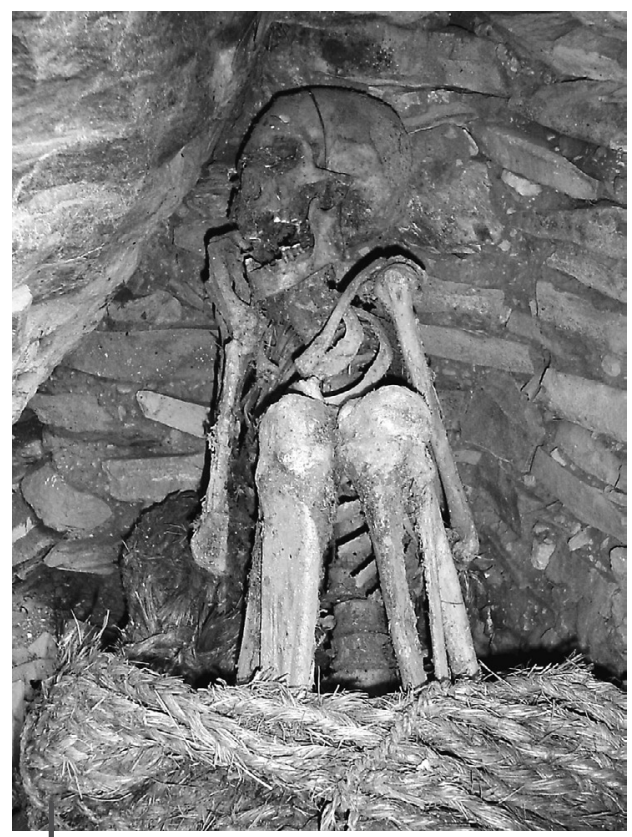

Figura 3 - «Momia» de la tumba 1 Foto: Frédéric Duchesne

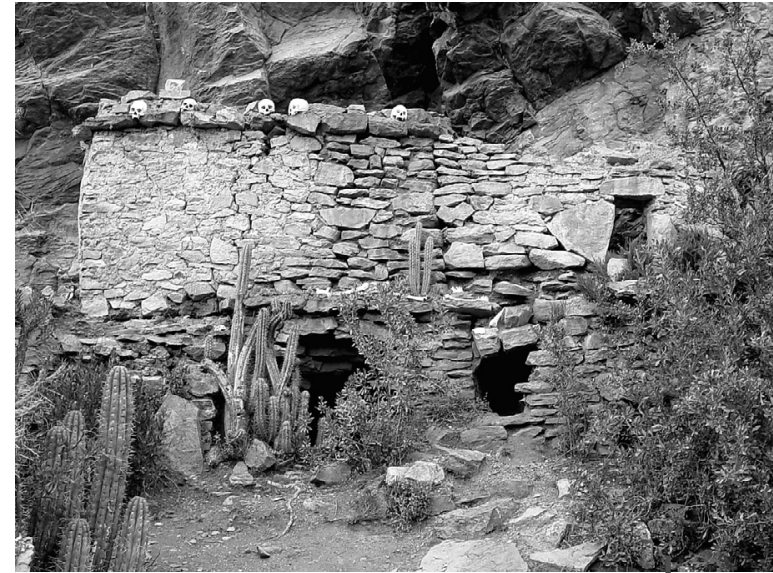

Figura 2 - Más elaborada, la tumba 14 se compone de varias cámaras

Foto: Frédéric Duchesne

El aspecto flexionado de los varios miembros inferiores completos que siguen en conexión anatómica y los numerosos restos de cestas en muchas tumbas muestran que todos los cuerpos fueron depositados de la misma manera que el cadáver intacto de la tumba 1: sentado en posición «fetal» ${ }^{9}$, manos sobre las mejillas, envuelto en una cesta vegetal. Los fragmentos de textiles de calidad que encontramos en las tumbas dejan suponer que los cuerpos estaban vestidos de ropa fina. Varios restos humanos (pie de niño de la tumba 1 , manos de la tumba 3), atestiguan un proceso de «momificación», en realidad un proceso de deshidratación/secamiento natural gracias a las condiciones climáticas.

Es razonable pensar que el cuerpo intacto —la «momia»- de la tumba 1 (fig. 3) se quedó en el lugar donde la depositaron. Está de espalda contra la pared, mirando hacía el interior de la cueva. Los cuerpos de los demás muertos estaban seguramente ubicados de la misma manera dentro de

9 Término utilizado por su comodidad descriptiva, sin referencia ninguna a cualquier implicación sobre el sentido de la muerte como símbolo de «renacimiento». Agrego que al morir, los cuerpo adoptan naturalmente una posición flexionada y abarquillada; los músculos flexioneros teniendo más fuerza que los músculos extensores. Así sin un dispositivo especial y sin manipulaciones para mantener el cuerpo muerto extendido, su posición normal será la de un «feto». 
la sepultura, a manera de un círculo de cadáveres. Un documento de archivo puede apoyar esta hipótesis.

A unos $80 \mathrm{~km}$ de Coporaque, en el pueblo de Andagua, varios procesos de idolatrías tuvieron lugar entre 1750 y 175410 . Descubriendo que los indígenas del pueblo seguían yendo a las antiguas tumbas de sus antepasados para honrarles, los españoles se apresuraron en destruir las tumbas y quemar las viejas momias. Sin embargo los extirpadores dejaron valiosas descripciones. Como en Coporaque, parece que las tumbas tenían el aspecto de pequeña casa, o de cueva ubicada en falda de la montaña y tapada con cal y canto:

«Dicho mochadero [...] era casa de la antigüedad pequeña que al parecer servía de retiro pues solo se componía de un cuarto todo labrado de piedras, y dentro del se hallaron los vestigios siguientes una cabeza de gentil o persona humana circundada de coca fresca y próximo a ella otra calavera» (AAA, documentos de Andagua, f. 114r).

«[...] en el lugar que llaman Quisguarani, [...] en un lugar y situación inculta, entre las ásperas de Peña, que lo circulaban, [...] quitó unas piedras y por boca estrecha se descubrió una cueva de bastante buque en donde estaban varios cuerpos de indios gentiles» (AAA, documentos de Andagua, f. 112v).

Todas las sepulturas en Andagua eran colectivas11. La grande mayoría de las momias están descritas en posición sentada, las manos puestas en las mejillas'12. Los cuerpos estaban vestidos13, rodeados de platos, ollas, jarras 14 y frecuentemente abastecidos en coca, alcohol y «otras porquerías» 15 . Y efectivamente, los cadáveres se hallaban sentados en círculo alrededor de una «mesa de piedra» donde depositaban las ofrendas 16 .

Las descripciones de las sepulturas de Andagua son comparables a los restos de las tumbas de Coporaque en cuanto a su organización interior.

En Sibayo, en el mismo valle del Colca a unos 20 km al este de Coporaque, la antropóloga AnneMarie Brougère (que agradezco por su valiosa información) encontró un cuerpo intacto en una tumba (fig. 4) muy parecido al de Coporaque y a lo que Paul Marcoy dibujó (fig. 5).

El explorador francés que vio las tumbas intactas, también describió y dibujó su interior:

«Cada tumba del tipo de éste en que nos encontrábamos estaba destinada a una docena de individuos, cuyos cuerpos, embalsamados con Chenopodium ambrosioides de los valles vecinos y portando sus vestidos o un saco tejido con hojas de totora y escotado a la

10 Verdadera ruina de archivo, este muy valioso documento, a pesar de ser incompleto, está «conservado», sin ser catalogado, en los Archivos del Arzobispado de Arequipa. No tiene nombre (los primeros folios desaparecieron).

11 «[...] se descubrió una cueva de bastante buque en donde estauan varios cuerpos de yndios gentiles, unos tendidos, y otros sentados» (AAA, documentos de Andagua, f. 112v).

12 «...] mandé sacar al citado cuerpo que puesto fuera del la cueva se reconoció ser de mujer sentada con las dos manos puestas en ambas mejillas de la cara [...]» (AAA, documentos de Andagua, f. 112v).

$13 \ll[\ldots]$ tienen baxios mochaderos en cuevas de gentiles los que estan intactos vestidos yndios e yndias con ropa a su usansa antigua que los dichos yndios de Andagua les ha puesto las vestiduras [...]» (AAA, documentos de Andagua, f. 16v).

14 «[...] fue al dho serro en donde alló una cueva, y entro de ella muchisimos gentiles con sus ollas y jarros a los lados [...]» (AAA, documentos de Andagua, f. 14v).

15 «[...] ban a sus mochaderos a adorar a los Gentiles llevando coca, chicha, vino y aguardientes [...]» (AAA, documentos de Andagua, f. 9r); «[...] alló una cueba en donde entró y alló unos Gentiles sentados, unos con cantaros de chicha en las manos, y otros con vino y otras porquerias [...]» (AAA, documentos de Andagua, f. 10v); «[...] dicho cadaver tenia puesta una montera de camellon y anascoto negro sobre la caueza con bastante yerba dela coca metida en la boca [...]» (AAA, documentos de Andagua, f. 128v).

16 «[...] otro mochadero esta a la parte de un lugar Ilamado Quinchaña auoyo abajo de las faldas de un bolcan que esta de manifiesto, es publico y notorio de que es una cueba grande a donde ay varios cadaveres de ynfieles que estan rodeados a una mesa grande hecha de piedras, a donde ponen lo que ofrendan de chicha coca y otros efectos de lanas de colores [...]» (AAA, documentos de Andagua, f. 18r). 


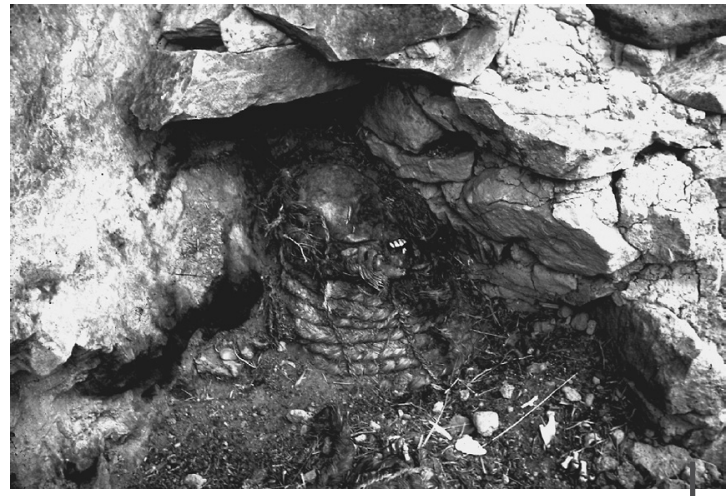

Figura 4 - «Momia» de Sibayo, 1978 Foto: Anne-Marie Brougère altura del rostro, se hallaban sentados en círculo y, tocándose con los pies figuraban los radios de un rueda. Cada muerto tenía junto a sí, a manera de provisiones y utensilios domésticos, mazorcas de maíz, un jarro para chicha, una cazuela y una cuchara» (Marcoy, 2001 [1869]: 138).

Esos documentos nos permiten llenar algunos silencios de la arqueología. Las informaciones proporcionadas por los documentos de Andagua y de Paul Marcoy aclaran los datos de Coporaque. Podemos pensar en efecto que las momias estaban colocadas en círculo, una al costado de la otra, la espalda pegada a la pared (fig. 6) del mismo modo que la «momia» de la tumba 1. Los artefactos ya no se hallan presentes en las tumbas pero se trataba probablemente de ofrendas de coca, chicha, maíz, sebo, parecidas a las descritas en las fuentes históricas.

Marcoy insistía sobre la mezcla en las tumbas de varones y mujeres, distinguiéndose los unos de los otros por sus ajuares funerarios:

«Cada muerto tenía junto a sí, a manera de provisiones y utensilios domésticos, mazorcas de maíz, un jarro para chicha, una cazuela y una cuchara. Si era un hombre, se añadía una honda, una macana o masa, aparejos de caza o de pesca y un rollo de trenzas de lana. Si era una mujer, se ponía a su lado un canastillo hecho con tallos de jarava, ovillos de lana de llama, lanzaderas y agujas de tejer hechas con largas espinas negras del cactus quisco» (Marcoy, 2001 [1869]: 139).

Las tumbas de Coporaque contienen huesos de pelvis completos. Algunos tienen caracteres marcadamente femeninos, pero solo un análisis antropológico podría confirmar si esas sepulturas eran efectivamente mixtas. Encontramos otra vez un argumento en la relación de Andagua donde los sepulcros son también colectivos y mixtos:

«[...] y el nombro que les ha puesto a estos cadaveres ynfieles es decirle camaq que quiere decir redemptos y por otro nombre les llaman Capachica a la estatua baronil, y a la mujer la llaman Cuiaqmama [...]» (AAA, documentos de Andagua, f. 17v).

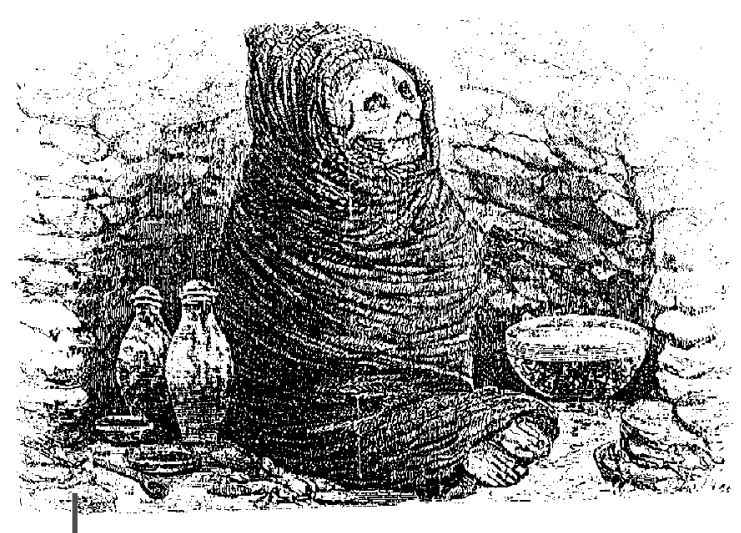

Figura 5 - «Momia aymara» según Macroy (2001 [1869]: 61)

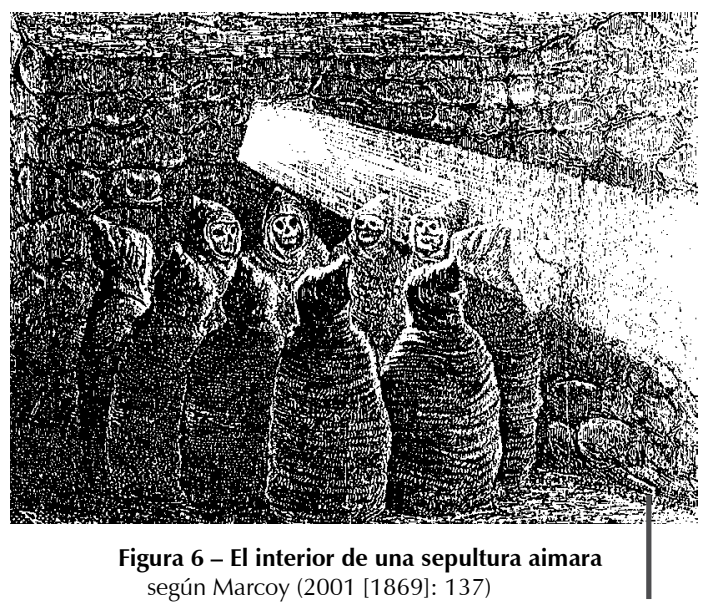

según Marcoy (2001 [1869]: 137) 


\section{TUMBAS DE COPORAQUE Y CHULLPAS}

Este tipo de entierros parece generalizarse durante el Intermedio Tardío en todos los Andes, desde Chachapoyas en el norte del Perú hasta el norte del Chile; desde la costa, hasta la ceja de selva (Isbell, 1997). Muchos cronistas (Cieza de León, 1988 [1553]; Polo de Ondegardo, 1917 [1571]; Mercado de Peñaloza, 1965 [1586]; Álvarez, 1998 [1588]; Guamán Poma de Ayala, 1980 [1615]; Ramos Gavilán, 1976 [1621]) describen tales sepulturas, todavía utilizadas hasta muy tarde en la Colonia, pero pocos les dan un nombre, y son indiferentemente descritas como torre, bóveda, casa. Sin embargo, el vocablo aimara chullpa — que según Ludovico Bertonio (1984 [1612]) calificaba en el siglo XVI y XVII un sepulcro (sin más precisión)— se usará para calificar las torres funerarias del altiplano.

Los pocos estudios que fueron dedicados a este tipo de tumbas fuera del altiplano utilizaron también el termino de chullpa. Entre otros, Herman Trimborn (1969) exploró las «chullpas» de Atiquipa, en la costa del departamento de Arequipa, y Maciej Sobczik (2000) hizo un amplio catálogo de las «chullpas» del Coropuna en el mismo departamento. Ya en los años 60, Máximo Neira $(1961 ; 1964 ; 1990)$ había notado sepulturas sobrealzadas en la zona de Collaguas, llamándolas chullpas, a la manera de sus homólogas altiplánicas. Al describir unas sepulturas de Coporaque, Wernke (2003) utilizó también ese mismo término. Chullpa está ahora considerado como la palabra genérica para describir cada tipo de torre o casa funeraria edificada sobre el suelo, generalización que a nuestros ojos borra importantes diferencias, tantos funcionales como simbólicas entre tumbas que reflejaban realidades distintas.

El caso de Coporaque nos da un ejemplo revelante. Un rasgo mayor de las chullpas del altiplano está ligado a la función de aquellas construcciones en el espacio. Hyslop (1977: 152) fue el primero en considerar el posible papel de las chullpas como marcador territorial. Efectivamente es muy probable que una chullpa (o un conjunto de chullpas), más allá de su función de mausoleo y de lugar de culto, tuviera una interacción con su entorno geográfico, un significativo en el espacio (que queda todavía por explicitar). Esas torres, visibles desde lejos, estructuraban el vasto espacio llano del altiplano, teniendo un sentido y una función que las distinguían de otras construcciones sobrealzadas de otros entornos geográficos.

Las casas funerarias de Coporaque tienen una situación totalmente diferente a la de las torres del altiplano: están totalmente escondidas en el paisaje, totalmente invisibles desde lejos, entreveradas en la roca, y de difícil acceso. Es decir que no estructuraban el espacio sino que lo utilizaban. Si un nombre genérico tendría que servir para designar esas construcciones, más conveniente sería el de machay, término que califica las cuevas-tumbas tapadas en las faldas de las montañas según las fuentes etnohistóricas ${ }^{17}$. Así las torres del altiplano y las casas funerarias de Coporaque, fuera de su función de albergar los difuntos y de constituir un lugar de culto, no tienen un papel idéntico para las sociedades que las edificaron.

Sin embargo, las sepulturas collaguas que describía Marcoy, llamándolas también «chullpas», tenían efectivamente todos los rasgos de las torres altiplánicas. En este caso los collaguas edificaban también sepulturas en lugares abiertos, visibles desde lejos. Entonces, si la relación tumbasespacio era tan fundamental ipor qué los collaguas que vivían cerca de Coporaque edificaron, a diferencia de los collaguas de Marcoy, sus tumbas en lugares escondidos en la falda de un espolón cuando hubieran podido sin dificultades construirlas en la meseta a campo abierto encima del espolón? Según la configuración del sitio, parece que en Coporaque eligieron el lugar que tenía el mejor punto de vista posible hacia el Huarancate, que al contrario no se divisa netamente desde la meseta. Así el rasgo predominante de la sepultura sería en este caso su orientación.

Existen entonces en la región Collaguas varios tipos de edificios funerarios: las chullpas (tipo Marcoy), los machayes (tipo Coporaque) que pueden variar en tamaño (sitio funerario 1 y 2),

17 Ver especialmente las extirpaciones de idolatrías de Cajatambo publicadas por Duviols (1986; 2003). 
que también encontramos fuera de la región Collaguas, en Andagua y alrededor del Coropuna18. No sabemos si esta variedad de sepulturas (que fueron ciertamente de uso contemporáneo) se debe atribuir a diferencias culturales ligadas a grupos étnicos diferentes o a una distinción social.

Sea lo que sea, el uso de la palabra chullpa para caracterizar todas las sepulturas sobreelevadas cuya utilización se difunda durante el Intermedio Tardío en una larga zona esconde una realidad más compleja y deja suponer — con abuso— una homogeneidad cultural de los Andes meridionales (considerando que las creencias hacia la muerte y las prácticas funerarias constituyen un fuerte revelador cultural y un reflejo de las sociedades). A pesar de la impresión de uniformidad que dan las crónicas (en efecto, Guamán Poma decía por ejemplo que la gente del Condesuyo enterraba sus difuntos de la misma manera que la del Collasuyo19) y de los muchos puntos en comunes que notamos entre las sepulturas de Coporaque y las chullpas (sepulcros sobrealzados, abiertos, orientados hacía un cerro o el oriente, posición «fetal» del cadáver envuelto en cesta, pintura interior en las tumbas), la diferencia fundamental del papel de aquellas tumbas en el espacio que hemos sacado a la luz nos impide utilizar el término chullpa como término genérico.

\section{4. ¿DISTINCIÓN SOCIAL EN LA MUERTE?}

Las tumbas de Coporaque, aunque vaciadas de contenido, eran probablemente todas colectivas. Por ejemplo, la tumba 7, a pesar de su saqueo contiene todavía por lo menos 16 individuos. En el caso de las chullpas, los estudios han considerado generalmente que los entierros colectivos revelaban una práctica sacrificial y que se trataba de tumbas de la élite.

El padre Bartolomé Álvarez, quien ofició cerca del lago Poopó, cuenta esta antigua tradición:

«Solían los curacas principales, cuando moría algún principal curaca, hacer que en el aposento del muerto se encerracen las mancebas que habían sido de aquel que estaba muriendo. A las cuales las cercaban otras mujeres; dándoles a comer coca y a beber acua, las hacían morir borrachas y ahogadas desta comida y bebida, diciendo "come, come y bebe presto y mucho, que has de ir a servir al malco - que

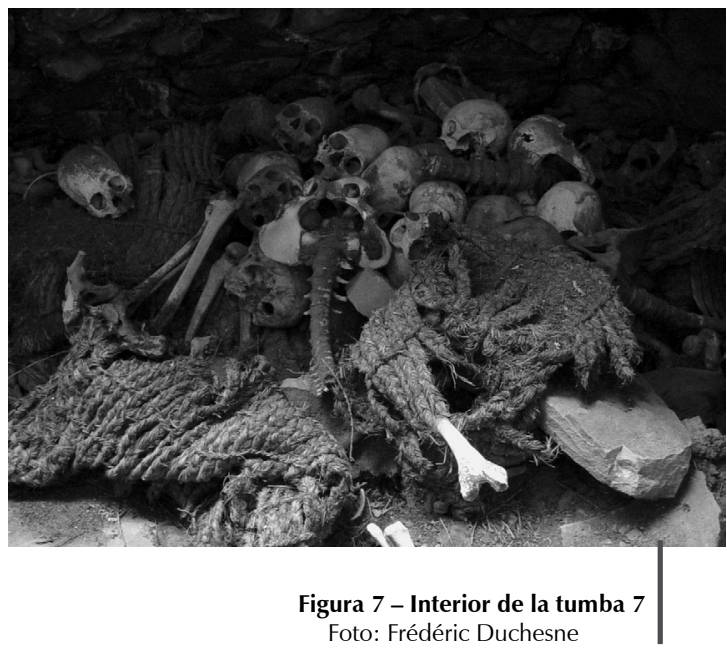
quiere decir 'señor'—; está de partida y has de ir a servirle allá donde va; que, si tú no vas, no lleva quien le sirva". Y así mataban a muchas, y las enterraban con ellos en sus sepulcros» (Álvarez, 1998 [1588], cap. 165: 94).

Luego, afirma que esta costumbre sigue haciéndose a finales del siglo XVI, y habla de rumores sobre tales sacrificios en el pueblo de Chuquibamba, cerca del nevado Coropuna, vecino de la región de los Collaguas

${ }^{18}$ El estudio de Sobczik muestra una gran variedad de tumbas en las región del Coropuna. Las del sitio de Culunche —que llama chullpa de colmena— son muy parecidas a las de Coporaque (Sobczyk, 2000: 45, 49-50).

19 «Cómo fue enterrado los yndios de Conde Suyos: Es como y de la manera que de como de los Colla Suyos [...]» (Guamán Poma, 1980 [1615]: f. 296). 
«Después que yo estoy en este reino, lo he oído decir en dos partes que lo han hecho curacas, y ha habido sospecha dello y se ha murmurado. Lo uno fue en un pueblo que se dice Calamarca; lo otro en el obispado del Cuzco, en un pueblo que se dice Chuquibamba» (Álvarez, 1998 [1588], cap. 166: 94).

En Coporaque, los restos de mujeres, de niños que he descubierto, podrían así ser, según esta misma lógica, considerados como los sacrificios que acompañaron a un curaca collagua en la muerte. Podríamos entonces considerar que las tumbas semi-subterráneas del «sitio funerario 1», de concepción menos elaborada, podrían ser las de gente de menor estatuto. En efecto, así concluye Wernke basándose en criterios de monumentalidad y generalizando20 (no considera al aspecto sacrificial, ya que no descubrió — según su trabajo — las tumbas no reventadas). Sin embargo es necesario plantearse algunos cuestionamientos antes de concluir tan abruptamente sin tener argumentos determinantes.

No se intentó hasta ahora averiguar de modo suficiente, gracias a excavaciones y análisis antropológicos precisos (por ejemplo con los métodos experimentales desde unas dos décadas por Henry Duday, Claude Masset y sus seguidores [Duday \& Masset, 1987; Cruzeby et al., 2000]), si en las tumbas colectivas los cuerpos fueron depositados de manera simultánea o sucesiva.

Un entierro colectivo simultáneo supondría, ya sea la muerte de varios individuos al mismo tiempo, lo que implica un hecho extraordinario, como una guerra, una epidemia o sacrificios, ya sea que los cuerpos de varias personas muertas en diferentes momentos sean depositados a la vez en la misma tumba. Este último caso supone dos etapas en el proceso funerario: la práctica de entierro primario y de entierro secundario (Hertz, 1907), lo que fue común en los Andes (Duchesne, 1999; 2000). Hasta el momento, no se intentó responder a esta pregunta importante en la arqueología funeraria andina. Sin embargo, Guamán Poma de Ayala nos da una indicación. Sus dibujos de los entierros del Condesuyo, Collasuyo, Chinchasuyo muestran ceremonias de depósito de un muerto en una tumba sobreelevada que está ya ocupada por otro muerto totalmente descompuesto (Guamán Poma, 1980 [1615]: 289, 293 y 295). Siguiendo Guamán Poma, tendríamos ejemplos de entierros sucesivos en tumbas colectivas. En este caso, no se trataría de sacrificios. Aquellas prácticas tendrían que ser estudiadas a través de análisis antropológicos sobre los huesos (eventuales marcas de corte, de golpe —a pesar de que según las fuentes, los sacrificios se hacían más por intoxicación-) que encontramos en aquellas tumbas.

Así el carácter colectivo de estas tumbas no puede constituir un argumento suficiente para atestiguar prácticas sacrificiales y deducir por lo tanto que se trata de personas de alto rango con sacrificios humanos. Entonces, quedaría el argumento de la monumentalidad, de la complejidad de estas casas funerarias y de la fuerza de trabajo que se necesita para construirlas, por oposición a las tumbas semi-subterráneas (del sitio 1 en nuestro caso). Pero si consideramos que la edificación de este tipo de tumba colectiva se hacía de manera también colectiva (como se hacían todas las tareas que concernían toda la comunidad), la rentabilidad para edificar tal sepulcro es mayor que la construcción de un pequeña tumba-semi subterránea individual de menos tamaño. Así, en nuestro caso, no podemos con ninguna certeza considerar esas tumbas como las de gente de alto estatuto21. Además, en Coporaque, el contenido de las tumbas muestra una homogeneidad que no deja ver una distinción entre los muertos.

Sin embargo, si no se puede averiguar diferencias obvias dentro de los muertos de una misma sepultura, el sitio de Coporaque muestra una diferenciación entre los muertos de los diferentes sepulcros. Así la tumba 10 es la única del sitio que contiene cráneos deformados (fig. 8). Todas las demás calaveras de las otras tumbas no muestran deformación alguna. Los individuos enterrados

20 «Clearly, chullpas were reserved for high status individuals. Most commoners probably continued to be interred in the subterranean, rock-lined tombs» (Wernke, 2003: 227)

21 No hay que buscar sistemáticamente correspondencias entre las sociedades de los vivos y las de los muertos. Muchas sociedades muy jerarquizadas, como en la cultura musulmana, reservan un tratamiento igual a sus muertos. 


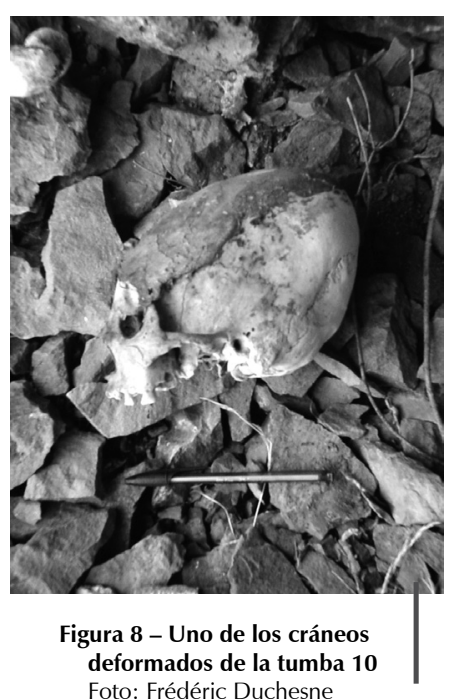

Foto: Frédéric Duchesne en las tumba 10 tenían el cráneo alargado, con deformación del tipo circunferencial o anular22.

Ulloa de Mogollón (1965 [1586]), que fue corregidor de la provincia de los collaguas en el siglo XVI, escribió efectivamente que los collaguas ponían una especie de «sombrero» muy estrecho en el cabeza de los niños para que este se alargara y quedara fino, esto - como lo anota sencillamente Ulloa de Mogollón- para tener la forma, del «volcán de donde salieron»23. Marcoy (2001[1869]: 137) también notó esta práctica:

«Entre las antiguas costumbres de esta nación, una de las más singulares, y que puede ayudar a que el etnógrafo descubra las huellas de su paso a través de ambos continentes, está la de deformar el cráneo de los recién nacidos y darles una forma cónica por medio de tablillas guarnecidas de algodón y amarradas con ligaduras. Los esqueletos de aimaras que se encuentra en la vecindad del mar [...] perfectamente reconocibles por su cabeza oblonga o en forma de huevo. Un huevo una de cuyas puntas formaría el facies puede dar una idea exacta al respecto».

Las deformaciones de cráneo son consideradas como un fuerte indicador étnico o social. Así Ulloa de Mogollón dice claramente que los cavanas, los vecinos de los collaguas, tenían costumbres diferentes y envolvían el cráneo con cuerdas apretadas para darle una forma ancha y plana24. Cieza de León (1988 [1553]: 227), al hablar de los collas, evoca prácticas similares a las de los collaguas:

«En las cabezas traen puestos unos bonetes a manera de los morteros, hechos de lana, que nombran chucos; tiénenlas todos muy largas y sin colodrillo, porque desde niños se las quebrantan y ponen como quieren».

Así en la tumba 10, tenemos a gente diferente de las demás sepulturas. ¿Podemos atribuir esta distinción a una diferencia de estatuto, la sociedad Collagua siendo, según Ulloa de Mogollón, dividida entre tres clases clasificatorias y jerárquicas 25 ? ¿O más bien deberíamos considerar que varias etnias o clanes o linajes compartían un mismo

22 Tipología en Dembo \& Imbellioni, 1938.

23 «Estos Collaguas, antes de la visita que se hizo por mando del excelentísimo virrey don Francisco de Toledo, traían en la cabeza unos que llamaban en su lengua chucos, a manera de sombreros muy altos sin falda ninguna, y para que se pudiesen tener en la cabeza, se la apretaban a los niños recién nacidos se la abusaban y adelgazaban alta y prolongada lo más que podían, para memoria que habían los cabezas de tener lo forma alta del volcán de donde salieron. Esto les está prohibido por ordenanza [...]» (Ulloa de Mogollón, 1965 [1586]: 327).

24 «Estos [los Cavanas] son muy diferentes en la cabeza a los Collaguas, porque recién nacidos los niños e niñas, se la atan muy recto y la hacen chata y ancha, muy fea y desproporcionada; la cual se atan con unas cuerdas blancas a manera de mechas, y dando muchas vueltas alrededor, quedan las cabezas ensanchadas [...] y [la cabeza de] estos Cavanas, ancha y chata» (Ulloa de Mogollón, 1965 [1586]: 327).

25 «Gobernábanse conforme a lo quel inga tenía puesto, que era, por sus ayllos e parcialidades nombraba de cada ayllo un cacique, y eran tres ayllos, llamados Collana, Pascana, Cayao; cada ayllo destos tenía trescientos indios y un principal a quien obedecían, y estos tres principales obedecían al cacique principal, que era sobre todos. Tenía el cacique principal mando y poder sobre todos los demás principales, los cuales le eran obedientísimos en todo lo que mandaba, así en las cosas de la guerra como en las cosas de justicia y castigo de delitos. Era este cacique puesto por el inga y sucedían sus hijos y a falta dellos sus hermanos, aunque fuese legítimo» (Ulloa de Mogollón, 1965 [1586]: 330). 
sitio funerario? Es imposible concluir sin investigaciones antropológicas. Sin embargo, algunos indicios en fuentes históricas dejan suponer que dentro de la necrópolis de Yuraqaqa, cada grupo (de parentesco, social o étnico), tenía su lugar preciso de entierro.

\section{5. ¿SEPULTURAS CLÁNICAS?}

En 1671, una extirpación de idolatrías llevada a cabo en el pueblo de Chicha26, ubicado a unos 100 kilómetros al oeste de Coporaque, nos dice que todos los indios veneran al volcán Solimana. Sin embargo, cada uno de esos indios responde durante los interrogatorios que adora a «su verdadero Dios», «al Dios de donde vienen sus padres», o sea al antepasado que fundó su grupo de parentesco, su ayllu. Así cada uno se va, según su antepasado, a un lugar de culto específico y diferente del de otra persona. Más explícitamente, en Andagua, pueblo vecino de Chicha, las investigaciones de las autoridades coloniales contra las idolatrías dejan claro que cada indio de Andagua tiene su cueva donde están sus antepasados y que cada familia tiene su propio lugar de culto27.

Del mismo modo, podemos pensar que en Coporaque, cada grupo de parentesco tenía un lugar específico para enterar los difuntos de su parentela. En este caso, tendríamos un uso de las tumbas de larga duración y la colectividad de aquellas sería el resultado del depósito sucesivo de los difuntos, como ya lo dejan suponer los dibujos de Guamán Poma de Ayala.

Podemos observar en varias tumbas (por los menos 1, 2, 14 y 15), una «aglutinación» horizontal o vertical de cámaras funerarias en un mismo edificio. Varias cámaras de una misma tumba fueron seguramente edificadas en diferentes momentos cronológicos (obviamente en las tumbas 2 y 14). Esto podría corresponder a una habilitación del edificio para recibir las generaciones siguientes. La tumba 7 y aún más la 2 muestran cámaras cerradas, a las cuales ya no se podía tener ningún acceso, o que se volvían invisibles, escondidas por una nueva cámara (tumba 2). ¿Podemos pensar que de algún modo las nuevas generaciones de muertos tomaban el sitio de las más remotas? De todos modos, esto nos muestra que a partir de un tiempo, los muertos de las cámaras escondidas ya no recibían ofrendas de parte de los vivos. ¿Olvido?

La lectura de varios documentos de extirpaciones de idolatrías del siglo XVII (Duviols, 1986; 2003), nos infunde pensar que después de una cierta temporada, que correspondía al tiempo necesario para que los difuntos hagan el viaje hacia sus antepasados, los muertos ya no eran honrados de una manera individual sino de manera colectiva y más bien simbólica (Duchesne, 1999; 2000). Si volvemos de nuevo a Andagua, vemos así que todas las momias femeninas se llamaban Cuyaqmama y todas las momias masculinas Capachica28. Todas estaban honradas sin distinción alguna y de forma colectiva.

En Coporaque, la configuración del sitio y el tamaño de las cámaras bastante reducido, nos dejan pensar que el culto a los muertos se hacía también de manera colectiva, y es posible que las cámaras cerradas del sitio de Yuraqaqa corresponden a un «olvido» de la individualidad de los difuntos, después de una o más generaciones, cuando aquellos ya están en el seno de sus antepasados.

Según interpretaciones de fuentes históricas (Duchesne, 1999; 2000), el muerto adquiere la ancestralidad, ayudado por las ofrendas de los sobrevivientes, después de un difícil viaje, una vez llegado donde descansan sus antepasados. Este sitio suele ser su mismo lugar de origen. Esta vuelta al lugar de nacimiento, a la pacarina, está muy a menudo asimilado a un cerro, hasta

26 «Declaraciones sobre la práctica de la hechicería e idolatría por los indios del pueblo de Chichas (provincia de Condesuyos de Arequipa», BNL, 1671, B1701.

27 «[...] tienen baxios mochaderos en cuevas de gentiles los que estan intactos vestidos yndios e yndias con ropa a su usansa antigua que los dichos yndios de Andagua les ha puesto las vestidaras y cada familia tiene separado sus mochaderos», AAA, documento de Andagua, f. 16r.

28 «[...] y el nombro que les ha puesto a estos cadaveres ynfieles [...] les Ilaman Capachua (Capachica?) a la estatua baronil, y ala mujer la llaman Cuyaqmama [...]», documento de Andagua, f. 17v. El sufijo Khuya- puede traducirse por «sentir compasión». 
donde camina el difunto a menudo por debajo de la tierra, por las aperturas, las bocas abiertas de la tierra.

La localización de la tumbas de Yuraqaqa, en las faldas de un cerro orientado al este y hacia un cerro (el Huarancate), dos lugares de origen primordiales según la cosmovisión andina y el deseo manifiesto de los constructores de esas tumbas de dedicar cada apertura a sus difuntos, ilustran muy bien esa creencia.

Aquellas tumbas eran lugar de culto para los muertos y/o los antepasados. Después del depósito de un difunto, acompañado según las fuentes etnohistóricas de varios ritos de separación/expulsión (Duchesne, 1999; 2000), los vivos volvían a la sepultura, o para depositar un nuevo difunto — suponemos del mismo linaje- o celebrar el «cabo de año» del difunto, lo que corresponde a una nueva ceremonia realizada después de una temporada variable (iel tiempo de duelo?) que consagra la entrada del difunto en el mundo de los antepasados (Duchesne, 1999; 2000). Cada ceremonia implicaba la participación de toda la «comunidad» según las fuentes, pero que podemos tal vez reducir al linaje del difunto. Así las tumbas pueden ser consideradas como un lugar de paso hacía el otro mundo, lo que acabamos de ver en Coporaque y que pueden constituir un lugar de comunión, de revitalización de la identidad del linaje. Las tumbas de Coporaque — aceptadas como sepulturas clánicas - pueden ciertamente ser consideradas como los lugares de memoria de los ayllu.

\section{DESCRIPCION DE LAS TUMBAS DE YURAQAQA ${ }^{29}$}

\section{1. Tumba 1}

No se puede observar más que unos $50 \mathrm{~cm}$ de la parte superior, la parte inferior siendo cubierta por tierra y piedras. El muro norte mide $50 \mathrm{~cm}$ de largo, el muro sur $120 \mathrm{~cm}$ y la fachada este unos $600 \mathrm{~cm}$. Los muros tienen $40 \mathrm{~cm}$ de ancho. Está divida en dos cámaras por una pared de $50 \mathrm{~cm}$ de espeso. En su mayor extensión, la camera norte mide $280 \mathrm{~cm}$ de largo y la camera sur $110 \mathrm{~cm}$. El techo, formado de grandes piedras planas, como se puede todavía averiguar en la tumba 2, ha sido roto durante el saqueo.

Los restos arqueológicos en esas cámaras se hallan a unos $70 \mathrm{~cm}$ de profundidad (lo que no corresponde a su real profundidad). Cada una tiene una entrada de $40 \mathrm{~cm}$ de ancho.

La tumba 1 contiene mucho material óseo perteneciendo a varios individuos (por lo menos siete). Dentro de la cantidad de huesos, llama la atención el pie momificado de un joven. Se nota que muchos huesos están todavía en conexión anatómica, sobre todo vértebras y un par de manos cuyos huesos están en perfecta conexión. Se ha podido ver 8 miembros inferiores completos (fémur, tibia, fibula) en conexión, que tienen la particularidad de ser doblados. El hallazgo principal de este recorrido se halla en esta tumba. Es una momia completa, ubicada en la parte norte. Estaba envuelta completamente en una cesta que ha sido abierta, tal vez por los huaqueros. Está sentada en la dicha posición «fetal»: piernas dobladas, rodillas a la altura de la cara, manos en las mejillas.

Notamos también la presencia de una trenza de cabellos negros. Hay varios artefactos, como textiles (marrón o rojo, unos bicolores crema/marrón) de baja calidad y varias cestas pero no hemos visto ningún fragmento de cerámica, ni otros objetos de madera o metálicos.

La cámara sur contiene varios huesos, la más notable siendo una columna vertebral completa en conexión con el hueso coxal complete (parece de mujer). Hay también textiles marrones y cestas.

${ }^{29}$ Las tumbas están descritas en su orden geográfico, desde del norte hasta el sur de la falda del espolón. 


\section{2. Tumba 2}

Está construida en la entrada de una cueva natural, tapándola. Es de planta más o menos cuadrada de unos $130 \mathrm{~cm}$ de lado. Su altura visible es de $210 \mathrm{~cm}$.

Parece que ha sido construida en dos etapas. Una primera cámara que se eleva a aproximadamente a $100 \mathrm{~cm}$ de altura fue tapada por piedras largas. Otra construcción fue edificada sobre esta primera tumba, tal vez para tapar la cueva natural y el acceso a otra cámara localizada en dicha cueva, atrás de la primera cámara y separada de ella por un muro de $140 \mathrm{~cm}$ de alto y de $120 \mathrm{~cm}$ de largo.

Los restos del edificio están tapados por piedras y tierra en la superficie. Se encuentran unos pocos huesos humanos, textiles y cestas. Los huesos pertenecen a individuos jóvenes. Al pie de esta chullpa se encuentran también huesos de jóvenes.

La cueva contiene muchos restos humanos: por lo menos tres cráneos (uno está todavía bajo tierra, y sobresale el hueso parietal), cuatro piernas completas doblas, vértebras en conexión, una columna vertebral con caja toráxica en conexión que tiene una extraña ruptura $\left(90^{\circ}\right)$ en la parte toráxica. ¿Golpe fuerte, patología grave o manipulación posmortem? Contiene también restos de cestas y de textiles.

\section{3. Tumba 3}

Esta sepultura está a unos $6 \mathrm{~m}$ al sur de la tumba 2. La fachada mide $320 \mathrm{~cm}$ y los muros norte y sur unos $150 \mathrm{~cm}$. Queda solamente la base. La cámara está totalmente cubierta por tierra y piedras. Se puede ver varios huesos sobresaliendo de la tierra, dentro de los cuales se aprecian un par de manos momificadas.

\section{4. Tumba 4}

Unos metros arriba de la tumba 3, se halla una larga y alta cueva $(400 \mathrm{~cm}$ de largo, $300 \mathrm{~cm}$ de profundidad, $800 \mathrm{~cm}$ de altura en sus mayores dimensiones) de muy difícil acceso. Estaba cerrada por la pared de una construcción idéntica a la de las otras sepulturas como lo muestran los numerosos bloques de piedras derrumbadas. Muchos huesos humanos cubren toda la superficie de la cueva y de sus alrededores.

\section{5. Tumba 5}

Está constituida por un solo muro cerrando una cueva natural. En su mayor extensión, la fachada mide $234 \mathrm{~cm}$ de largo y $274 \mathrm{~cm}$ de alto. La cumbre de la fachada tiene una cornisa de $10 \mathrm{~cm}$ de ancho y el techo está formado ya por la cueva misma, por largas láminas de piedras de grandes dimensiones. La fachada tiene dos aperturas a niveles de altura distintos. Puede ser que hubo dos etapas en la construcción de este edificio. Hay una parte baja, cubierta en su base por escombros, constituida por solo un muro recto de $130 \mathrm{~cm}$ de largo y con una entrada de $40 \mathrm{~cm}$ de ancho delimitada por tres dinteles de largas piedras. Sobre este muro se edificó una parte superior que avanza más hacia el este y bajando hasta la base del primer muro en la parte norte (también cubierta por escombros) y que tiene la particularidad de encorvarse es su parte sur, dando así un aspecto vagamente circular. Vista la configuración del sitio, esto parece la mejor solución para apoyar la construcción al cerro. Esta parte superior tiene una entrada parcialmente destruida. Queda el dintel superior $(50 \mathrm{~cm})$ y el dintel norte $(40 \mathrm{~cm})$. La fachada tiene unos rasgos de argamasa que probablemente cubría toda su superficie. En el interior se distingue por lo menos 2 niveles. No queda claro a simple vista (muchos escombros) si las dos partes exteriores 
correspondían a dos niveles interiores. Pero notamos que debajo del nivel inferior hay un nivel subterráneo. Por dentro, podemos apreciar el intento de falsa bóveda para construir el techo.

El material arqueológico está cubierto por tierra y escombros. Sin embargo se puede ver muchos huesos humanos y restos de cestas.

\section{6. Tumba 6}

Se encuentra a unos $10 \mathrm{~m}$ de la sepultura descrita arriba. Esta casa funeraria se apoya también sobre la roca, que la cierra en su parte norte y oeste y parcialmente en el lado sur donde un pequeño muro de $100 \mathrm{~cm} \times 100 \mathrm{~cm}$ cierra el edificio. El edificio está en parte cubierto por la roca y en la parte sur fue tapado por largas piedras (hoy destruidas). La fachada este se apoya también sobre la roca en su parte sur. En sus mayores dimensiones mide unos $400 \mathrm{~cm}$ de largo y $270 \mathrm{~cm}$ de alto. Tiene una cornisa y dos aperturas. Una, a modo de «ventana» de $60 \mathrm{~cm}$ x $50 \mathrm{~cm}$, formada por dos dinteles en sus extremidades verticales. El acceso se hacía seguramente por la apertura colocada en la base del edificio. Está hoy destruida en parte, pero queda todavía el dintel superior. Al lado de esta supuesta puerta, el edifico avanza hacia el Este, constituyendo una especie de pequeña plataforma (?). No se puede averiguar bien la base del edifico, siendo cubierta por muchas plantas y varios cactus.

En el interior hay una primera «planta» donde están varios huesos humanos. Está perforada por una especie de pozo conduciendo a la puerta. Mide unos $70 \mathrm{~cm}$ de profundidad, $280 \mathrm{~cm}$ de ancho y $210 \mathrm{~cm}$ de largo. Contiene también huesos humanos, dentro de los cuales un cráneo con una probable marca de golpe (ireciente o antigua?).

\section{7. Tumba 7}

Se ubica a $300 \mathrm{~cm}$ al sur de la casa funeraria 2. Está en su casi totalidad cubierta por plantas y cactus, así que fue imposible tener una vista de su aspecto exterior. Su acceso se hizo por el techo.

Los constructores han aprovechado una cavidad natural en la roca que han cerrado en su lado este con un muro encorvado ligeramente de unos $400 \mathrm{~cm}$ de largo y de $400 \mathrm{~cm}$ de alto. La mayor dimensión entre el muro y la roca alcanza $300 \mathrm{~cm}$. El edifico fue también tapado por una lámina de piedras largas y hay un intento de constituir una falsa bóveda. Contrariamente a los demás edificios del sitio no hay aberturas evidentes hacia el este.

Este monumento contiene una cantidad impresionante de restos humanos. A simple vista, se ha contado por lo menos diez y seis cráneos (aparentemente sin deformaciones). El alto número de piernas dobladas y de restos de cestas del mismo tipo que la momia de la tumba 1, nos indica que los cadáveres estaban todos envueltos y sentados.

\section{8. Tumba 8}

Es una cueva cuya pequeña apertura estaba cerrada por unos bloques de piedra. Se encuentran varios huesos.

\section{9. Tumba 9}

Los constructores han aprovechado una gran cueva con amplia apertura. Por su altura $(800 \mathrm{~cm})$ tuvieron que edificar una alta terraza de piedra sobre la cual construyeron la sepultura. Aquella mide $300 \mathrm{~cm}$ de altura y $400 \mathrm{~cm}$ de largo. Tiene dos pisos separados por monolitos y visible desde el exterior por una cornisa y dos aperturas delimitadas por dinteles a distintas alturas. El nivel inferior tiene $170 \mathrm{~cm}$ de altura y fue edificado con falsa bóveda que soporta el peso de los monolitos. El nivel superior mide $120 \mathrm{~cm}$ de altura y está tapado por la roca. Contiene todavía unos pocos huesos humanos. 


\section{10. Tumba 10}

Cinco metros al sur, se halla una grande tumba casi totalmente devastada y cubierta por sus propios restos. Fue así imposible estimar su aspecto y sus dimensiones. Notamos que las piedras utilizadas por su construcción tienen un color gris, lo que es único en todo el sitio. Corresponde precisamente al color de la roca en este lugar, lo que significa que los constructores utilizaban los materiales disponibles del lugar mismo donde edificaban la tumba. Entre los pedazos de piedras y los numerosos huesos dispersos, se hallan 6 cráneos que muestran claras deformaciones.

\section{11. Tumba 11}

Un poco más al sur, quedan los muros norte y sur de una tumba prácticamente derrumbada. Se apoyaba también en la pared de la montaña y su superficie era aproximadamente de $70 \mathrm{~cm}$ de ancho y $300 \mathrm{~cm}$ de largo. El muro sur muestra inicio de falsa bóveda, la cual soportaba seguramente monolitos de piedras que formaban el techo.

\section{12. Tumba 12}

Es una pequeña cámara cuadrada, apoyada a la pared de la montaña. Mide unos $200 \mathrm{~cm}$ de lado. La parte superior inicia una falsa bóveda, que según el pequeño tamaño de la cámara la tapaba totalmente.

\section{13. Tumba 13}

Otra tumba derrumbada, muestra sin embargo un mejor aspecto que sus vecinas. $200 \mathrm{~cm}$ sobresalen del suelo. Su configuración es trapezoidal, del mismo modo que la tumba 1. El muro sur mide 200, la fachada $480 \mathrm{~cm}$ y el muro norte $70 \mathrm{~cm}$. Está compuesta por dos cámaras funerarias separadas por un muro de unos $40 \mathrm{~cm}$ de ancho. La del sur contiene una apertura, pero no la del norte. Algunos huesos largos — fibulas, fémures, tibias- cubren todavía la superficie de la cámara sur.

\section{14. Tumba 14}

Se trata sin duda de la tumba más preservada. Dos pisos estructuran el edifico que tiene una altura de $330 \mathrm{~cm}$ y más de $550 \mathrm{~cm}$ de largo. Cada piso tiene dos cámaras funerarias independientes (superficie media de $2 \mathrm{~m}$ ). Cada una tiene una apertura, menos la cámara sur del segundo nivel que estaba totalmente cerrada. La cámara norte del piso inferior tiene un nicho delimitado por dinteles y su muro oeste muestra rasgos de una capa de estuco blanco cubierto de rojo. Una cornisa, todavía visible en la parte sur, coronaba la tumba. Monolitos cubrían el edificio como la muestra la parte sur. El muro norte está todavía cubierto por una capa de argamasa que tal vez cubría todo el exterior del edificio.

Dos pequeños muros fueron agregados al muro sur para constituir una cámara suplementaria de pequeña dimensión y totalmente cerrada.

Contiene huesos largos, vértebras en conexión anatómica, y varios cráneos — sin ninguna deformación-que han sido expuestos a su cumbre. 


\section{15. Tumba 15}

Esta tumba tenía seguramente la misma configuración que la tumba 14, pero toda la parte (¿cámara?) norte se derrumbó. El edificio tiene dos pisos, pero el nivel inferior se encuentra hoy bajo tierra y solo sobresalen unos $100 \mathrm{~cm}$ que dejan ver la parte superior de una apertura. La parte superior mide $320 \mathrm{~cm}$ de largo y $200 \mathrm{~cm}$ de alto. Tiene una apertura y una cornisa. También fue reventada y los huesos largos y cráneos están expuestos.

\section{16. Tumbas 16 y 17}

De estructura idéntica, pegada la una a la otra, podrían ser dos cámaras de una misma tumba. Toda la parte inferior está bajo tierra pero desde arriba, el techo siendo derrumbado, se nota una grande profundidad que deja suponer la existencia de más de un nivel. Las cámaras miden unos $200 \mathrm{~cm}$ de largos y $80 \mathrm{~cm}$ de ancho. Contienen varios huesos largos, cráneos, costillas, vértebras, muchas de las cuales en conexión y varios restos de cestas y de textiles de color rojo.

\section{17. Tumba 18}

La mayor parte de esta tumba se encuentra también bajo tierra. Sin embargo se nota dos pequeñas cámaras de $200 \mathrm{~cm}$ de lado. La cámara norte, compuesta de dos muros (este y norte) se apoya sobre un ángulo formado por la roca. No presenta evidencia de apertura, el acceso visible en la esquina norte-este siendo el resultado de un derrumbe. Así, fue tal vez tapada por la cámara sur que se apoya en el muro este de la cámara norte y tiene una apertura en su fachada. Una apertura — hecha seguramente por los saqueadores al pie de la cámara norte- muestra un nivel inferior amplio semi-subterráneo que deja suponer una estructura más compleja. Contiene muchos huesos entremezclados y cestas.

\section{Referencias citadas}

Archivo del Arzobispado de Arequipa, Documento de Andagua (no publicado, no ccatalogado, sin referencia).

ÁLVAREZ, B., 1998 [1588] - De las costumbres y conversión de los indios del Perú: memorial a Felipe II, 462 p.; Madrid: Polifemo - Ministerio de educación y cultura, Dirección general del libro, archivos y biblioteca.

BENAVIDES, M., 1989 - Las visitas a los Yanquecollaguas de los siglos XVI y XVII: organización social y tenencia de tierras. Bulletin de l'Institut Français d'Études Andines, 18 (2): 241 267.

BENAVIDES, M., 1992 - Dualidad social e ideologica en la provincia de Collaguas, 1570-1731. Revista de Historia y Cultura del Mueso Nacional de Arqueología, Antropología e Historia del Perú, 21: 127-160.

BERTONIO, L., 1984 [1612] - Vocabulario de la lengua Aymara, 946 p.; Cochabamba: Centro de estudios de la realidad económica y social, CERES - Institut Français d'Études Andines, IFEA - Museo nacional de etnografía y folklore, MUSEF.

CIEZA DE LEÓN, P., 1988 [1553] - La crónica del Perú, 262 p.; Lima: Nueva Biblioteca Peruana. 
COOK, D. N., 1982 - The people of the Colca valley: a population study; Boulder: Westview Press.

CRUBEZY, E., LORANS, E., MASSET, C., PERRIN, F. \& TRANOY, L. 2000 - Archéologie funéraire, 208 p.; Paris: Errance.

DENEVAN, W. M. (ed.), 1986 - The cultural ecology, archaeology, and history of terracing and terrace abandonment in the Colca valley of Southern Peru, vol. 1; Madison: Departamento de Geografía, Universidad de Wisconsin. Technical report to the National Science Foundation and the National Geographic Society.

DENEVAN, W. M. (ed.), 1988 - The cultural ecology, archaeology, and history of terracing and terrace abandonment in the Colca valley of Southern Peru, vol. 2. Madison: Departamento de Geografía, Universidad de Wisconsin. Technical report to the National Science Foundation and the National Geographic Society.

DEMBO, A. \& IMBELLIONI, J., 1938 - Deformaciones intencionales del cuerpo humano de carácter étnico; Buenos Aires: Biblioteca del Americanista Moderno José ANSI.

D'ORBIGNY, A., 2002 [1839] - Viaje a la América Meridional: Brasil, República del Uruguay, República Argentina, La Patagonia, República de Chile, República de Bolivia, República del Perú realizado de 1826 a 1833, 4 tomos, 1762 p.; Lima, La Paz: IFEA - Plural.

DUCHESNE, F., 1999 - Acculturations et survivances religieuse, Cajatambo (Pérou) au XVII siècle, 98 p.; Paris: IHEAL. Tesis de Maestría.

DUCHESNE, F., 2000 - La Mort et les morts dans les sources coloniales, 90 p.; Paris: IHEAL. Memoria de DEA.

DUDAY, H. \& MASSET, C., 1987 - Anthropologie physique et archéologie, 406 p.; Paris: édition du CNRS

DUVIOLS, P., 1986 - Cultura andina y represión: Procesos y visitas de idolatrías y hechicerías, siglo XVII, 568 p.; Cuzco: Centro Bartolomé de las Casas, CBC.

DUVIOLS, P., 2003 - Procesos y visitas de idolatrías. Cajatambo, siglo XVII con documentos y anexos, 882 p.; Lima: IFEA - PUCP.

GALDOS RODRÍGUEZ, G., 1985 - Kuntisuyu. Lo que encontraron los españoles; Arequipa: Fundación Manuel J. Bustamante de la Fuente.

GISBERT, T., 1994 - El señorío de los Carangas y los chullpares del Río Lauca. Revista Andina, 12 (2): 427-485.

GUAMÁN POMA DE AYALA, F., 1980 [1615] - El primer nueva crónica i buen gobierno, 1175 p.; México: IEP - Siglo Veintiuno.

HERTZ, R., 1928 [1907] - Contribution à l'étude sur le représentation collective de la mort. Sociologie religieuse et folklore: 16-93.

HYSLOP, J., 1976 - An archaeological investigation of the Lupaqa kingdom and its origins; New York: Universidad de Columbia. Tesis de doctorado.

HYSLOP, J., 1977 - Chulpas of the Lupaca Zone of the Peruvian High Plateau. Journal of field Archaeology, 4: 149-170.

ISBELL, W. H., 1997 - Mummies and mortuary monuments. A postprocessual prehistory of central andean social organization, 391 p.; Austin: University of Texas Press.

KESSELI, R., LIUHA, P. \& ROSSI, M., 1999 - Archaeological and geographical research of precolumbian (AD 1200-1532). Grave towers or Chullpa on the Bolivian High Plateau in the years 1989-1998. Preliminary report. Dig it all: Papers dedicated to Ari Siiriäinen: 335348; Helsinki: The Finnish Antiquarian Society, The Archaeological Society of Finland.

KESSELI, R., SARANAGA MENESES, J., KORPISAARI, A. \& BUSTAMENTE, J., 2003 - Informe sobre las investigaciones arqueológicas realizadas en torres funerarias de piedra de Taramaya, Provincia Los Andes, agosto 2002. Noticias del proyecto arqueológico finlandés-boliviano en la amazona bolivian II: 97-120; Helsinki: Departmento de Aqueología, Universidad de Helsinki. 
MARCOY, P., 2001 [1869] - Viaje a través de América del sur, del océano Pacífico al océano Atlántico, t. 1, 567 p.; Lima: IFEA - BCRP - PUCP - Centro amazónico de antropología y aplicación práctica, CAAP.

MERCADO DE PEÑALOSA, P. de, 1965 [1586] - Relación de la provincia de los Pacajes. In: Relaciones Geográficas de Indias-Perú (Jiménez de la Espada, ed.), t. 1: 335-341; Madrid: Atlas. BAE 183.

NEIRA AVENDAÑO, M., 1961 - Los Collaguas; Arequipa: Universidad Nacional de San Agustín. Tesis de Maestría.

NEIRA AVENDAÑO M., 1990 - Arequipa prehispánica. In: Historia General de Arequipa (Neira Avendaño et al., eds): 5-184; Arequipa: Fundación M. J. Bustamante de la Fuente.

NORDENSKIÖLD, E., 1953 [1906] - Investigaciones arqueológicas en la región fronteriza del Perú y Bolivia, 163 p.; La Paz: Biblioteca Paceña, Alcaldía Municipal.

ORÉ, L. J., 1992 [1598] - Symbolo catholico indiano, 462 p.; Lima: Australis.

PÄRSSINEN, M., 1993 - Torres funerarias decoradas en Caquiaviri. Pumapunku, 5-6: 9-31.

PÄRSSINEN, M., 2003 - Copacabana iel Nuevo Tiwanaku? Hacia una comprensión multidisciplinaria sobre las secuencias culturales post-tiwanacotas de Pacasa, Bolivia. In: Los Andes: cincuenta años después (1953-2003). Homenaje a John Murra (Lorandi, Salazar-Soler \& Wachtel, comp.): 229-280; Lima: PUCP.

PEASE, F. (ed.), 1977 - Collaguas I, 487 p.; Lima: PUCP.

POLO DE ONDEGARDO, J., 1916 [1571] - Informaciones acerca de la Religión y gobierno de los Incas, 208 p.; Lima: Carlos Romero. Colección de libros y documentos referentes a la Historia del Perú, tomo III.

RAMOS GAVILÁN, A., 1976 [1621] - Historia de Nuestra Señora de Copacabana, 264 p.; La Paz: Academia Boliviana de la Historia.

ROBINSON, D., 2003 - Collaguas II, Lari Collaguas: economía, sociedad y población, 16041605, 452 p.; Lima, Nueva York: PUCP - Universidad de Siracusa.

RYDEN, S., 1947 - Archaeological reasearches in the highlands of Bolivia, 559 p.; Götteborg: Eanders Boktryckeri Akiebolag.

SOBCZYK, M., 2001 - Arquitectura funeraria prehispánica en la región del Nevado Coropuna, 290 p.; Varsovia: ANDES, Boletín de la Misión Arqueológica Andina, Universidad de Varsovia.

SQUIER, G., 1974 [1877] - Un viaje por tierras incaicas: crónica de una expedición arqueológica (1863-1865), 318 p.; La Paz : Los amigos del libro.

TORERO, A., 2002 - Idiomas de los Andes: lingüística e historia, 565 p.; Lima: IFEA - Editorial Horizonte.

TREACY, J.,1994 - Las chacras de Coporaque: andenería y riego en el Valle del Colca, 298 p.; Lima: IEP.

TRIMBORN, H., 1969 - Die Chullpa von Atiquipa. In: Verhandlungen des XXXVIII: internationalen Amerikanistenkongresses: 393-405; Stuttgart, München.

TSCHOPIK, M., 1946 - Some notes on the archaeology of the Department of Puno, Perú. Papers of the Peabody Museum of American Archaeology and Ethnology, 27 (3): 53 p.; Cambridge, Massachusetts: Harvard University Press

ULLOA DE MOGOLLÓN, J. de, 1965 [1586] - Relación de la provincia de los Collaguas para la descripción de las indias que su majestad manda hacer. In: Relaciones Geográficas de Indias-Perú (Marco Jiménez de la Espada, ed.), t. 1: 326-333; Madrid: Atlas. BAE 183.

WERNKE, S., 2003 - An archeo-history of Andean community and landscape: the late prehispanic and early colonial colca valley, Peru, 664 p.; Madison: Universidad de Wisconsin. Tesis de Doctorado. 